\title{
Response of the neutral particle upper atmosphere to the solar eclipse of 7 March 1970
}

\author{
J. J. HoRvath \\ University of Michigan, Ann Arbor, Michigan 48105, U.S.A. \\ and \\ J. S. THEON \\ Goddard Space Flight Center, Greenbelt, Maryland 20771, U.S.A.
}

(Received 24 November 1971)

\begin{abstract}
A series of five pitot probes were launched from Wallops Island, Va. $\left(38^{\circ} \mathrm{N}\right)$ in conjunction with the solar eclipse, 7 March 1970 . Three soundings were programmed to occur at 40,80 and 100 per cent obscuration of the $S u n$ (at $100 \mathrm{~km}$ ) during a $42-\mathrm{min}$ period. The remaining two soundings were made $24 \mathrm{hr}$ before and after the eclipse. The five soundings yielded neutral particle pressure, temperature, and density profiles over the altitude regime $30-125 \mathrm{~km}$. Below $95 \mathrm{~km}$ the three density profiles resulting from the eclipse day launches had an average deviation of loss than 1.5 per cent. Above $95 \mathrm{~km}$ density changes of up to 20 per cent were observed. Such changes in density are comparable in magnitude to those normally observed over a period of several hours. On 10 March 1971, three additional pitot probes were launched from Wallops Island, Va. at times identical to those of the 1970 eclipse day. Comparison of the two sets of data should provide for a more objective analysis regarding atmospherie response to solar input.
\end{abstract}

\section{INTRODUCTION}

PrIor to 1970 , only one set of rocket soundings of the neutral atmosphere above $30 \mathrm{~km}$ during a solar eclipse had taken place (BALlard et al., 1969). These data indicated rather large temperature variations at the stratopause and in the lower mesosphere over the several hour period spanning the eclipse. The data presented here resulted from the launch of eight pitot probe payloads. Three payloads were expended within a 42-min period on 7 March 1970 from Wallops Island during the actual solar eclipse event. An additional set of three payloads was launched, again from Wallops Island, on 10 March 1971 at identical times corresponding to the eclipse launches. These two sets of launches are referred to as the eclipse series and the control series respectively. Two additional soundings, which were conducted at approximately $\pm 24 \mathrm{hr}$ from the eelipse event, were intended to monitor the conditions before and after the eclipse. The unexpectedly large day-to-day variability reduced the value of these two soundings for background comparison, necessitating the March 1971 series for this purpose. The significance of the 'control' series lies not in a direct comparison of the absolute values of the control profiles with the eclipse profiles, but rather to demonstrate that the short term variability of the upper atmosphere over Wallops Island in March is similar in both the control series during which the solar heating changed gradually, and the eclipse series during which the solar heating changed abruptly.

\section{Expertmental Teohnique}

A brief description of the pitot probe technique of upper atmosphere observation should be given. It is an aerodynamic technique which utilizes the continuous 
measurement of the impact or stagnation pressure on an ascending rocket payload moving at supersonic speeds. Using theory appropriate to the unique flow regimes encountered, compressible fluid theory in the continuum region and a modified thermal transpiration interpretation in the free molecular flow region, a continuous undisturbed neutral particle density profile can be obtained between 30 and $125 \mathrm{~km}$ (HoRvath et al., 1962). The absolute accuracy of the derived mass density profile is on the order of \pm 2 per cent up to $70 \mathrm{~km}, \pm 3$ per cent between 70 and $85 \mathrm{~km}, \pm 4$ per cent between 85 and $100 \mathrm{~km}$. Discussion of absolute errors above $100 \mathrm{~km}$ requires the treading of very thin ice. For the purpose of these data only relative variations are important. Assuming, then, that the major possible error sources above $100 \mathrm{~km}$, composition and horizontal winds, are constant in time over the $42 \mathrm{~min}$ observational period, the error is a function of sensor repeatability. Under this assumption, the assigned relative accuracy between observations within a series increases monotonically from \pm 4 per cent at $100 \mathrm{~km}$ to \pm 10 per cent at $125 \mathrm{~km}$.

Once the density profile has been determined, a temperature profile can be derived by downward integration of the hydrostatic equation.

\section{OBSERVATIONS}

The experimental objective was to determine the local neutral atmospheric response to a sudden removal of solar radiation. As luck would have it, not only did the solar eclipse take place, but very high levels of geomagnetic activity were occurring over the same time interval.

Figures 1 and 2 show the density profiles resulting from the two series. For convenience, the data are plotted as the ratio of the measured density to the value given in the 1962 U.S. Standard Atmosphere (Dudin et al., 1962). Below $90 \mathrm{~km}$ the standard deviation in the three density profiles for either series was less than \pm 2 per cent, or within the expected error flags of the measurement. The eclipse series continued to show very little variation all the way to $97 \mathrm{~km}$ while the control soundings (Fig. 2) indicate greater variability in the region $80-97 \mathrm{~km}$. Above $97 \mathrm{~km}$, reasonably large variations were observed in both sets of measurements. Note that at about $111 \mathrm{~km}$ an apparent 30 per cent decrease in density occurred in 27 min during the eclipse. Figure 3 shows a comparison between the eclipse and control series in terms of the standard deviations of density. As noted previously, the deviations below $90 \mathrm{~km}$ for each series are of the same order of magnitude, \pm 2 per cent and generally appear to be in phase. Note, especially, the large deviation of 6-7 per cent at $84-85 \mathrm{~km}$ in both series, while the absolute error in density at $85 \mathrm{~km}$ is not expected to be greater than $\pm 3-4$ per cent.

Between 90 and $100 \mathrm{~km}$, the control series exhibits larger deviations than the eclipse series. Above $100 \mathrm{~km}$, however, the eclipse density data include very large deviations. Again, at $111 \mathrm{~km}$ the 30 per cent density decrease that occurred in $27 \mathrm{~min}$ is reflected by a standard deviation of \pm 14.5 per cent.

Figures 4 and 5 show the temperature comparison for both 7 March 1970 and 10 March 1971. Below $105 \mathrm{~km}$ the small scale structure in each set of observations is very similar. Both contain wavelike variations with amplitudes on the order of $5^{\circ} \mathrm{K}$, and vertical wavelengths between 2 and $10 \mathrm{~km}$. Computation 


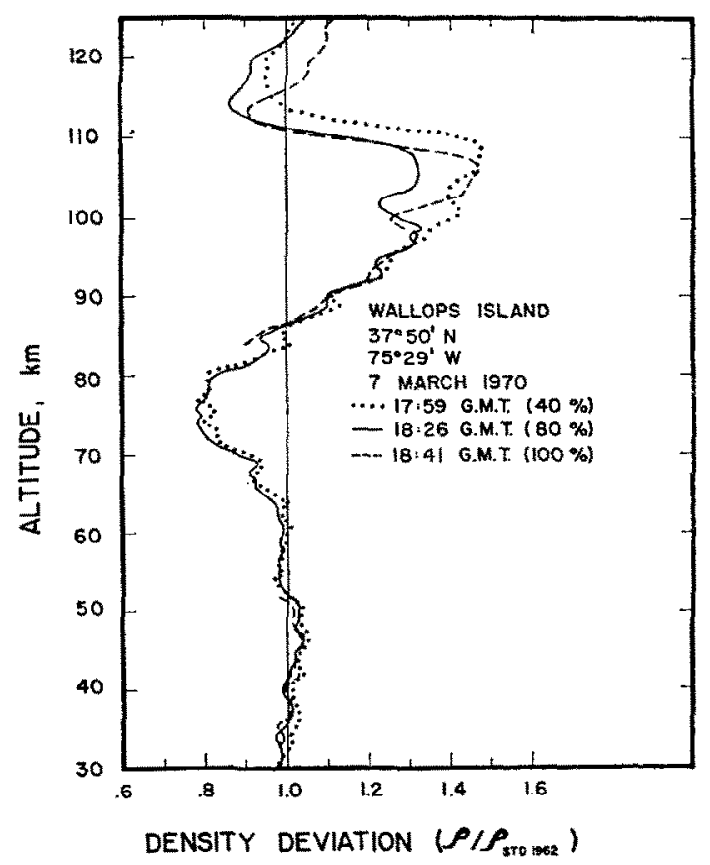

Fig. 1. Density profiles observed from Wallops Island on 7 March 1970 (eclipse day). The missing data between $52-84 \mathrm{~km}$ in the $1841 \mathrm{GMT}$ profile resulted from a payload malfunction. Density is plotted as a ratio to the 1962 U.S. Standard Atmosphere value for convenience.

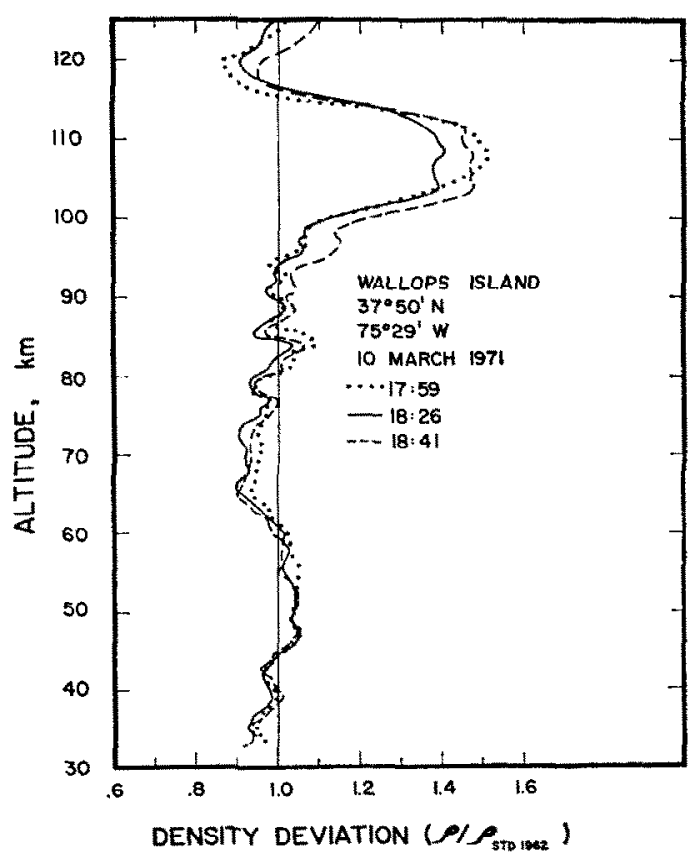

Fig. 2. Density profiles observed from Wallops Island on 10 March 1971 (control day). Density is plotted as a ratio to the 1962 U.S. Standard Atmosphere value for convenience. 


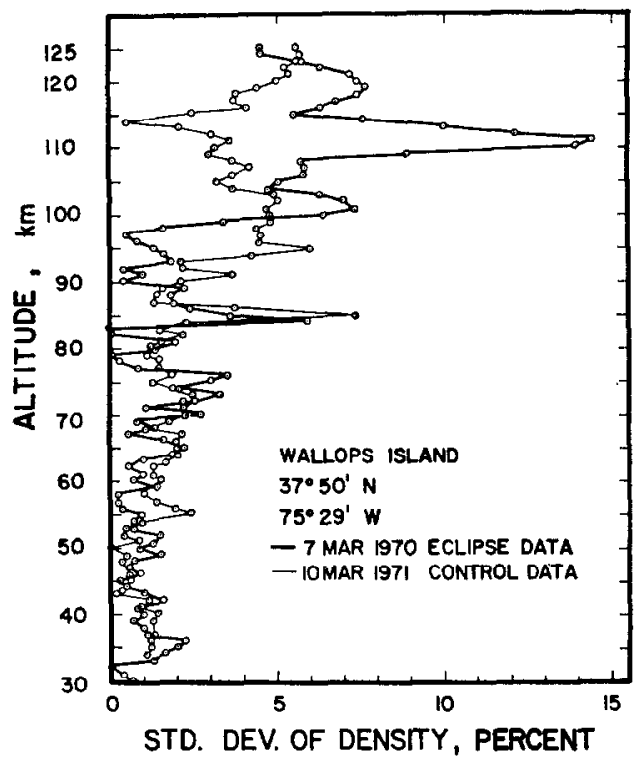

Fig. 3. The standard deviations of the observed density profiles as a function of altitude for the eclipse day (heavy curve) and the control day (light curve).

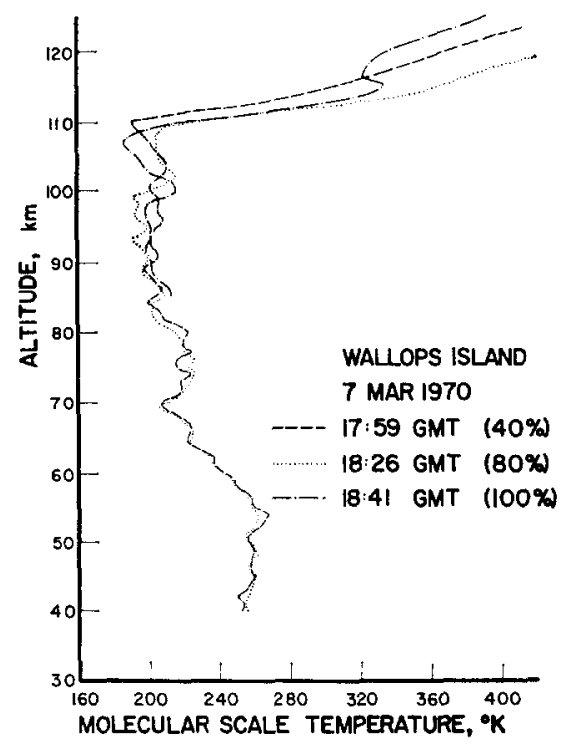

Fig. 4. Temperature profiles derived from the observed density profiles for the eclipse day. 


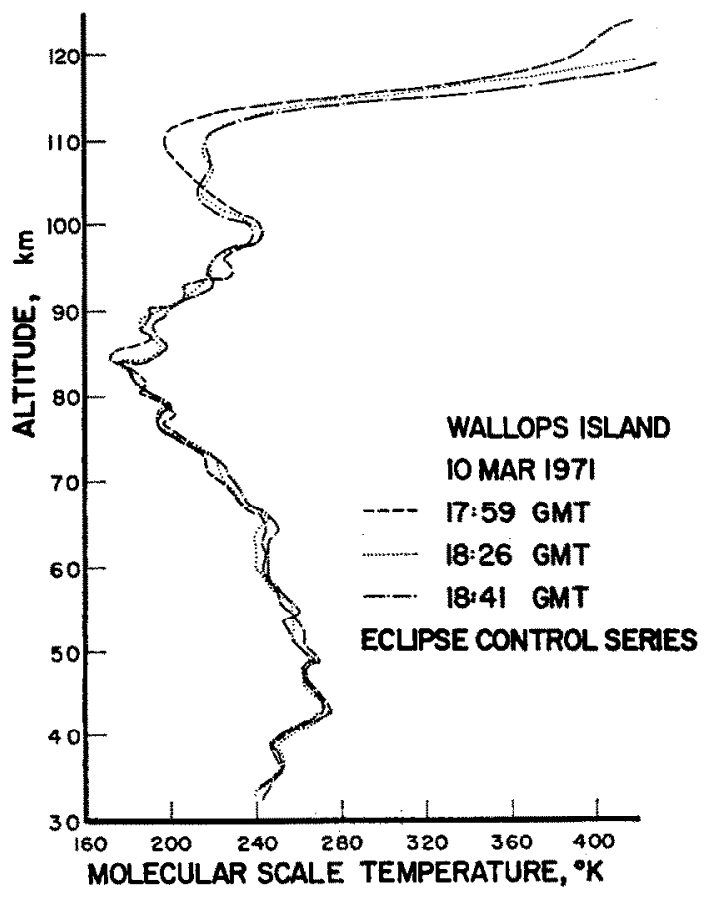

Fig. 5. Temperature profiles derived from the observed density profiles for the control day.

of mean temperature profiles for each series allows a comparison of standard deviations to be made between series. Below $80 \mathrm{~km}$, the average standard deviation for both series is less than $\pm 2 \cdot 5^{\circ} \mathrm{K}$, and increases to about $\pm 3 \cdot 5^{\circ} \mathrm{K}$ between 80 and $95 \mathrm{~km}$. Between 95 and $105 \mathrm{~km}$, the average standard deviation is $\pm 4^{\circ} \mathrm{K}$ and $\pm 7.7^{\circ} \mathrm{K}$ for the control and eclipse series respectively.

Below $105 \mathrm{~km}$, the temperature differences, observation to observation, are not large in either series. In addition, features in the small scale wave structure can, for the most part, be identified between observations within each series. Above $105 \mathrm{~km}$, the temperature structure for both series is consistent in gross character. However, definite wavelike features in the temperature structure exist in the third launch of the eclipse series at about $112 \mathrm{~km}$, and in the first launch of the control series at about $120 \mathrm{~km}$. A wavelike structure was also observed near $110 \mathrm{~km}$ on the day following the eclipse series (Fig. 6).

\section{Conclusions}

Based upon the comparison of all the data acquired and presented here, the following conclusions were reached:

(1) There were no detected effects of neutral atmospheric response attributable solely to the solar eclipse and/or the disturbed condition of the geomagnetic activity below $97 \mathrm{~km}$ during the $42 \mathrm{~min}$ observation period. 


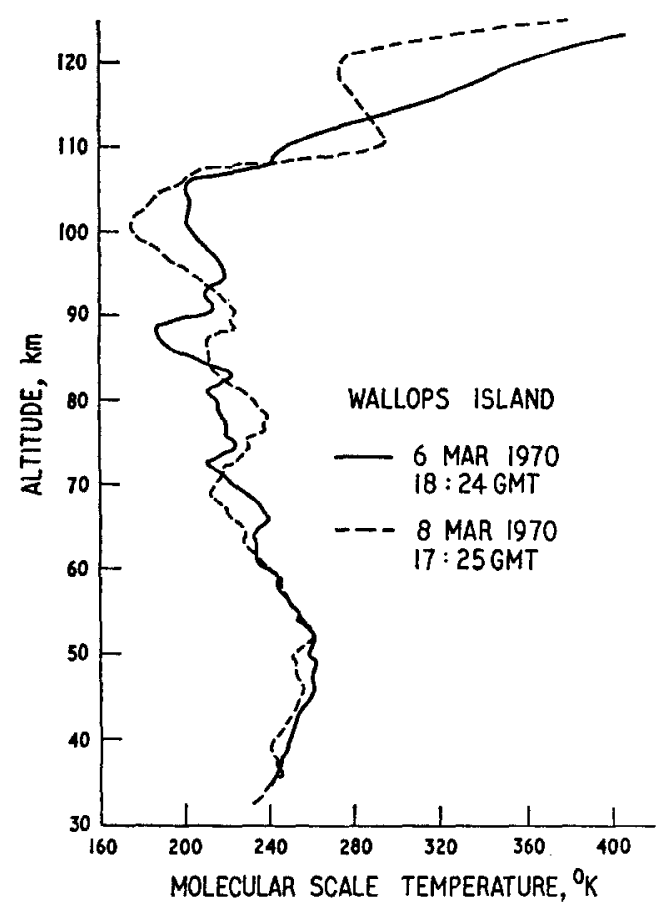

Fig. 6. Temperature profiles observed on 6 March 1970, 1824 GMT (full curve) and 8 March 1970, 1725 GMT (broken curve).

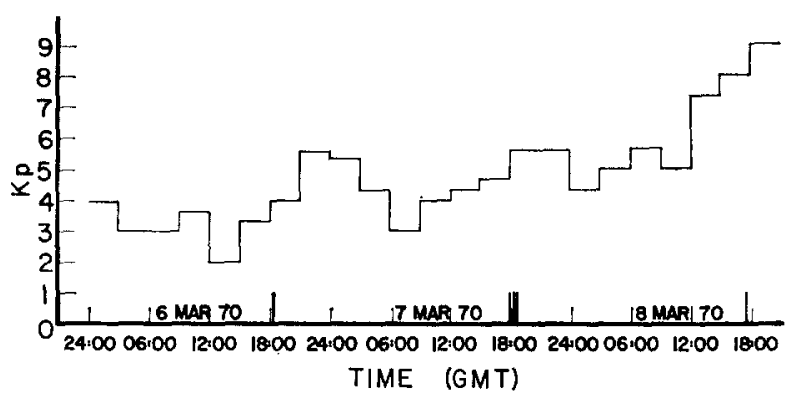

Fig. 7. Geomagnetic activity as a function of time on 6-8 March 1970.

(2) The evidence also indicates very little, if any, response of the neutral atmosphere between $97 \mathrm{~km}$ and $120 \mathrm{~km}$ due to the solar eclipse, since similar variations wcre obscrved in both series.

(3) The wave structure observed in the last measurement on eclipse day, and the more pronounced amplitude of a wavelike feature on 8 March 1970 might be related to the geomagnetic activity (see Fig. 7). However, it is more probable that the dynamic nature of that region of the atmosphere is such 
Response of the neutral particle upper atmosphere to the solar eclipse of 7 March $1970 \quad 599$ that changes in temperature and/or density of the order observed normally occur.

\section{REFERENCES}

BALLARD H. N. et al.

Durin M., SISSENwINE N. and WEXLER H.

Horvath J. J., Srmmons R. W. and Brace L. H.
$1969 \quad$ I. genphys. Res. 74, 711.

1962 U.S. Standard Atmosphere. U.S. Gov't Printing Office, Washington.

1962 Univ. of Michigan Rept. NS 1, Ann Arbor. 